\title{
Predictive value of complement profiles and anti-dsDNA in systemic lupus erythematosus
}

\author{
A J G SWAAK, 12 J GROENWOLD, ${ }^{2}$ AND W BRONSVELD
}

From the 'Department of Rheumatology, Dr Daniël den Hoed Kliniek, Rotterdam, The Netherlands; the ${ }^{2}$ Department of Autoimmune Diseases of the Central Laboratory of the Netherlands Red Cross Blood Transfusion Service, and Laboratory for Experimental and Clinical Immunology of the University of Amsterdam, Amsterdam, The Netherlands; and the ${ }^{3}$ Department of Internal Medicine, Free University Hospital, Amsterdam, The Netherlands

SUMMARY In a prospective study of 143 patients with systemic lupus erythematosus (SLE) the relation between clinical exacerbations, anti-dsDNA levels, and serum levels of complement components, C1q, C4, C3, C5, and C9 was investigated. In 33 out of these 143 patients a major clinical exacerbation of the disease developed. Evaluation of anti-dsDNA levels in relation to disease activity confirmed our earlier finding that anti-dsDNA levels rose before a major exacerbation and decreased after it. In the remaining 110 SLE patients a nearly constant anti-dsDNA level was seen, but none of these patients experienced a major exacerbation. In the 21 SLE patients who developed deterioration in renal function a decrease of $\mathrm{C} 4$ followed by decreases of $\mathrm{C} 1 \mathrm{q}$ and $\mathrm{C} 3$ levels was seen first, starting about 25 to 20 weeks before the first signs of renal involvement. In the $12 \mathrm{SLE}$ patients who developed an exacerbation without renal involvement an inconsistent profile of the complement components $\mathrm{C} 4, \mathrm{C} 1 \mathrm{q}$, and $\mathrm{C} 3$ was observed. C5 levels were hardly affected at : !1, while C9 levels were in general higher than normal during the exacerbation, irrespective of the type of exacerbation. These results show that, by following the complement and anti-dsDNA profiles, not only can exacerbations be predicted but also a pointer can be obtained about the pattern of disease well before the first clinical signs of an exacerbation appear.

Serum complement levels are often used as prognostic indicators and diagnostic aids in patients with systemic lupus erythematosus (SLE). Diminished serum complement activity $\left(\mathrm{CH}_{50}\right.$ titre) has been claimed to accompany or precede the onset of nephritis. ${ }^{1}$ Exacerbations of nephritis have also been described without a fall in the serum complement level. ${ }^{2}$ Specifically, the presence of low levels of $\mathrm{Clq}$ or $\mathrm{C} 4$ has been claimed to be a sign of the presence of renal disease or the tendency to develop it. ${ }^{34}$ In later studies lower mean levels of $\mathrm{C} 1 \mathrm{q}, \mathrm{C} 4$, and $\mathrm{C} 3$, but not of $\mathrm{C} 5$ and $\mathrm{C} 9$, were observed in SLE patients with renal involvement. ${ }^{56}$ In two prospective follow up studies normalisation of serum $\mathrm{CH}_{50}$ or $\mathrm{Clq}$ and $\mathrm{C} 3$ levels was associated with improvement in renal function. ${ }^{78} \mathrm{Up}$ till now there have been no available serial data, gathered in

Accepted for publication 9 October 1985.

Correspondence to Dr A J G Swaak. Dr Daniël den Hoed Klinick. Groene Hilledijk 301, 3075 EA Rotterdam. The Netherlands. a long term, prospective manner, involving a large group of patients with frequent serum sampling, on the profiles of the complement components $\mathrm{Clq}$, $\mathrm{C} 4, \mathrm{C} 3, \mathrm{C} 5$, and $\mathrm{C} 9$ in the periods preceding, during, and after disease exacerbations (renal and non-renal). In the present study the relation between the clinical course, the anti-dsDNA level, and the profile of the various complement components is described, with special regard to the period preceding exacerbations. An attempt has been made to answer the question whether or not the complement profile in combination with anti-dsDNA can predict an exacerbation and also its nature (renal versus nonrenal) at a stage well before the first clinical signs of the exacerbation appear.

\section{Patients and methods}

PATIENTS AND SERA

Patients were followed up clinically (by AJGS and WB) in three clinical centres in the Netherlands: the 
Department of Internal Medicine of the Slotervaart Hospital (Amsterdam), the Department of Internal Medicine of the Free University Hospital (Amsterdam), and the Department of Rheumatic Diseases of the Dr Daniël den Hoed Hospital (Rotterdam). Venous blood was collected from 143 patients meeting the preliminary criteria for the diagnosis of SLE. ${ }^{9}$ Samples from all these patients were obtained at four to six week intervals. After coagulation and centrifugation the sera were stored at $-20^{\circ} \mathrm{C}$.

When the patients developed additional complaints or manifestations of their disease the frequency of clinical and serological investigations was increased, if possible, to one to three week intervals. Disease activity was recorded without knowledge of the serological parameters, and treatment of the patients was not influenced by serological data. Signs of disease activity, medication, indications for dosage alterations, and routine clinical laboratory results were recorded on standard clinical record sheets. Exacerbations were defined by the occurrence of major disease features. ${ }^{810}$ Minor symptoms were mainly restricted to the musculoskeletal system and the skin, which could be controlled by an increase in prednisolone dosage of $5-15 \mathrm{mg} /$ day without the need for admission to hospital. Major features were characterised by at least one of the following: renal impairment, serositis, anaemia $(\mathrm{Hb}$ $<7 \mathrm{~g} / \mathrm{dl}(70 \mathrm{~g} / \mathrm{l})$ and/or leucopenia (white cell count $<4 \times 10^{9} / 1$ ) and/or thrombocytopenia (platelet count $\left.<50 \times 10^{9} / 1\right)$, neurological or psychiatric symptoms. These features always led to hospitalisation, and the dosage of prednisolone was increased to more than $20 \mathrm{mg} /$ day. Episodes in which the features were explained by causes other than SLE were excluded.

Patients with pre-existing renal involvement were considered to be inactive when no significant alterations took place in the creatinine values, proteinuria, and urine sediment. An increase in proteinuria or other evidence of further deterioration of renal function, in the absence of other causes (such as pyelonephritis not related to SLE), were recorded as exacerbations of renal disease.

Renal function was assumed to have deteriorated when urinary protein increased to at least $1 \mathrm{~g} / 24 \mathrm{~h}$, or when there was an increase in red blood cell (RBC) casts in the urinary sediment, or a decrease in glomerular filtration rate (GFR) of more than $20 \%$. Increase of urinary protein, sediment abnormalities, or decrease in GFR were considered significant only if observed on at least three consecutive days.

SERUM COMPLEMENT

$\mathrm{C} 1 \mathrm{q}, \mathrm{C} 3, \mathrm{C} 4, \mathrm{C} 5$, and $\mathrm{C} 9$ were determined by radial immunodiffusion with monospecific antisera against
$\mathrm{Clq}, \mathrm{C} 3 \mathrm{c}, \mathrm{C} 4, \mathrm{C} 5$, and C9 (Central Laboratory of the Netherlands Red Cross Blood Transfusion $\Rightarrow$ Service, lot Nos aC1q: KH43-02-PO2, aC3c: KH4115-POI, aC4: KH12-09-PO2, aC5: KH44-03-PO3, 을 and aC9: KH50-02-PO3). The values were ex- 흠 pressed as percentages of a standard pooled donor $\frac{\bar{\rho}}{\vec{D}}$ serum. Results obtained from 200 healthy blood $\stackrel{\Phi}{\varrho}$ donors yielded normal values (mean $\pm 2 \mathrm{SD}$ ) of 69-128\% for C1q, 37-144\% for C4, 66-124\% for C3, $73-135 \%$ for $\mathrm{C} 5$, and $68-133 \%$ for $\mathrm{C} 9$. For $\mathrm{C} 4, \mathrm{C} 5$, 을 and C9 these normal levels were used. Because $\vec{\omega}$ earlier studies had indicated that a level of $\mathrm{C} 3$ or C1q levels below $40 \%$ was always associated with $\frac{9}{2}$ renal involvement, ${ }^{8} 11$ this level was chosen to differentiate very low from decreased levels.

DETERMINATION OF ANTI-dSDNA

Anti-dsDNA was determined by the Farr assay, as modified by Aarden et al ${ }^{12}{ }^{3} \mathrm{H}$-Labelled assay, as 0 bacteriophage, $\mathrm{PM}_{2} \mathrm{DNA}$, with a molecular weight $\vec{z}$ of $5.9 \times 10^{6}$, was used as antigen. This ${ }^{3} \mathrm{H}$-labelled $\mathrm{PM}_{2}$ DNA was purified according to the method of $\vec{c}$ Espejo and Canelo ${ }^{13}$ and found to be free of ssDNA contamination. Up to $50 \mu$ l serum was incubated with $100 \mathrm{ng}{ }^{3} \mathrm{H}$-labelled dsPM $_{2}$ DNA. The total amount of antibody was expressed in units $/ \mathrm{ml}$. One unit is defined as the amount of anti-dsDNA that binds $30 \%$ of $100 \mathrm{ng} \mathrm{PM}_{2} \mathrm{DNA}$ under standard conditions.

RELATION BETWEEN ANTI-dSDNA LEVELS, COMPLEMENT LEVELS, AND DISEASE STATE (EXA CER B A TION)

The patients who experienced exacerbations were divided into two groups according to the presence or absence of renal involvement during the exacer- 0 bation. The moment of the first evidence of exacerbation was called time zero $(\mathrm{t}=0)$, corresponding 0 mostly to the highest dsDNA level. From this point the period before and after the exacerbation was 윽 divided into four week intervals. For each patient $D$ clinical and serological data were evaluated at the을 end of this investigation, from 24 weeks before to $24 \overline{\mathrm{N}}$ weeks after the exacerbation.

Complement levels were classified according to $N$ the normal values (low or normal), at four week $\mathrm{W}$ intervals. Results were then expressed as percen- $\sigma$ tages of the patients with normal or low levels at the defined periods before and after the exacerbation.

\section{Results}

ANALYSIS OF THE 143 PATIENTS STUDIED Over a period of six years we recorded 33 exacer- $\Omega$ bations in 143 patients. ${ }^{11}$ Of these 33,21 patients $\stackrel{\mathbb{D}}{2}$ developed a deterioration of the renal function in association with other symptoms, whereas $12 \%$ 
Table 1 Frequency and type of 33 exacerbations in 143 SLE patients

\begin{tabular}{lrrrlll}
\hline Clinical features & \multicolumn{2}{c}{ Group $I^{*}$} & & \multicolumn{2}{l}{ Group II* } \\
\cline { 6 - 7 } \cline { 6 - 7 } & No & $\%$ & & No & $\%$ \\
\hline Renal discase & 21 & 100 & & 0 & 0 \\
Hacmatological discase & 9 & 43 & 8 & 67 \\
Pleuritis or pericarditis, or both & 7 & 33 & 6 & 50 \\
Neurological or psychiatric. or both & 2 & 10 & 3 & 25 \\
\hline
\end{tabular}

${ }^{*}$ Group $\mathbf{I}=21$ patients who developed a deterioration of the renal function in association with other symptoms; group II $=12$ patients who showed exacerbations without signs of renal involvement.

patients showed exacerbations without signs of renal involvement. Table 1 shows the frequency of major symptoms in both groups of patients. Complement profiles were systematically studied only in these 33 patients, whereas anti-dsDNA levels were studied in all 143 patients. During the period of observation the anti-dsDNA levels in the 110 patients that did not develop a major exacerbation remained nearly constant, as reported in our previous study. ${ }^{14}$ Results obtained with the other 33 patients confirmed our previous finding that periods of major exacerbations were heralded by increasing antidsDNA levels, whereas concomitant with the actual development of these flares anti-dsDNA levels decreased rapidly (Figs 1 and 5). During this follow up study four patients developed a second exacerbation. Only the first was used in the analysis, lest these patients might influence the final results too strongly. Results obtained in those four exacerbations, however, were in agreement with the general results.

COMPLEMENT PROFILES OF 21 PATIENTS WITH RENAL INVOLVEMENT

Fig. 1 shows an example of the changes in the levels of the complement components seen in the patients who developed a deterioration in renal function. First there was a decrease of $\mathrm{Clq}$ and $\mathrm{C} 4$, later a decrease in $\mathrm{C} 3$. A relative decline in the $\mathrm{C} 5$ levels was also noted, though the levels remained within normal units. No change was observed in the C9 levels (data not shown).

Follow up data (profiles of the complement components) of all 21 patients, gathered as described in 'Patients and methods', have been combined in Fig. 2. This figure illustrates that for most of the 21 patients who developed renal disease the period preceding the exacerbation was characterised by decreasing $\mathrm{C} 1 \mathrm{q}$ and $\mathrm{C} 3$ levels. In nearly $80 \%$ of the patients $\mathrm{C} 4$ was already reduced 16 weeks before the onset of the exacerbation. At that point $\mathrm{C} 1 \mathrm{q}$ and
C3 were still 'normal' in $50 \%$ of the patients. At time zero $\mathrm{C} 1 \mathrm{q}, \mathrm{C} 4$, and $\mathrm{C} 3$ were decreased in $90 \%$ of the patients $(\mathrm{Clq} \leqslant 40 \%, \mathrm{C} 4 \leqslant 37 \%, \mathrm{C} 3 \leqslant 40 \%)$. In four of the 21 patients with exacerbations a discrepancy between the $\mathrm{Clq}$ and $\mathrm{C} 3$ profile was found: at $\mathrm{t}=0$ two patients had normal C1q levels,

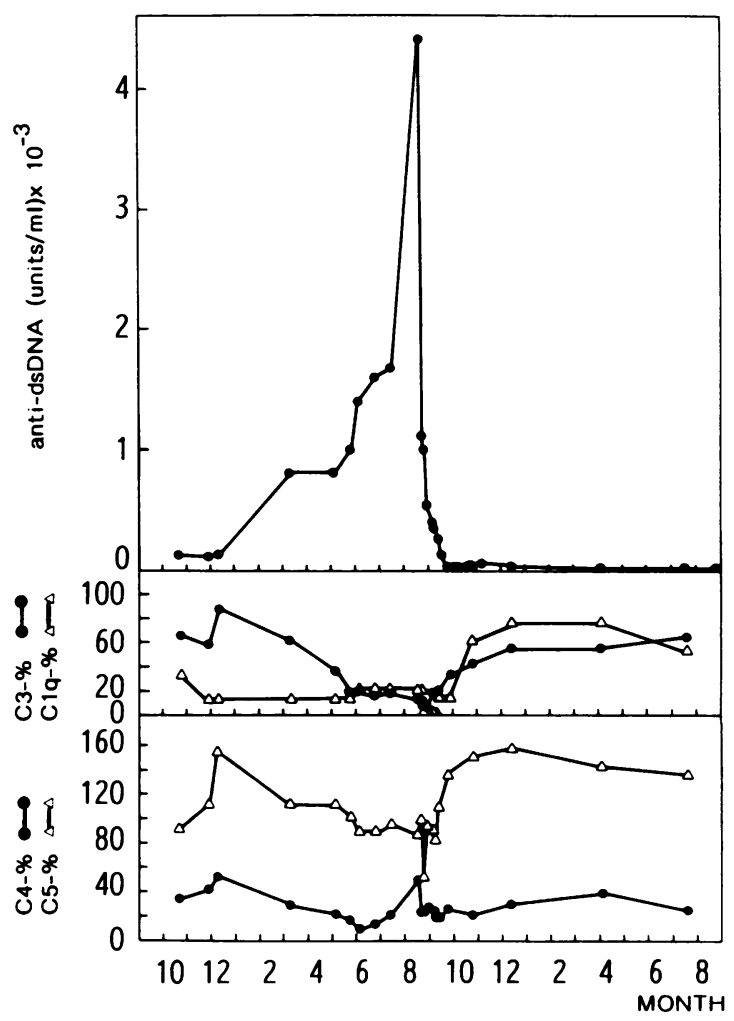

Fig. 1 Correlation between profiles of the complement components, anti-dsDNA, and course of the disease. A 24 year old female (patient 1) was admitted to hospital on 17 August 1981. For four years she had complained about her joints. Routine examination showed a positive $L E$ phenomenon and antinuclear antibodies. In May a butterfly rash developed as well as leucocytopenia $\left(2 \cdot 3 \times 10^{9} / l\right)$ and thrombocytopenia $\left(80 \times 10^{9} / 1\right)$. At this stage anti-dsDNA levels were increasing. After a holiday (in Italy) the features of discoid lupus erythematosus developed. The serum creatinine levels remained nearly constant (73-68 $\mu \mathrm{mol} / \mathrm{l})$ until 16 August 1981 (month 8, at which time the peak in anti-dsDNA level occurred); these increased to $100 \mu \mathrm{mol} / \mathrm{l}$ on 16 August, and a few days later to 124 umolll on 20 August and to 123 umol/ml on 23 August. Nephritis was confirmed by the presence of hyaline casts in her urine. Renal biopsies showed diffuse proliferative glomerulonephritis. Prednisolone therapy was started on 16 August 1981 with $40 \mathrm{mg}$ daily; later, the dose was increased to $100 \mathrm{mg}$ daily. On this therapy creatinine levels decreased to $95-100$ umolll. 


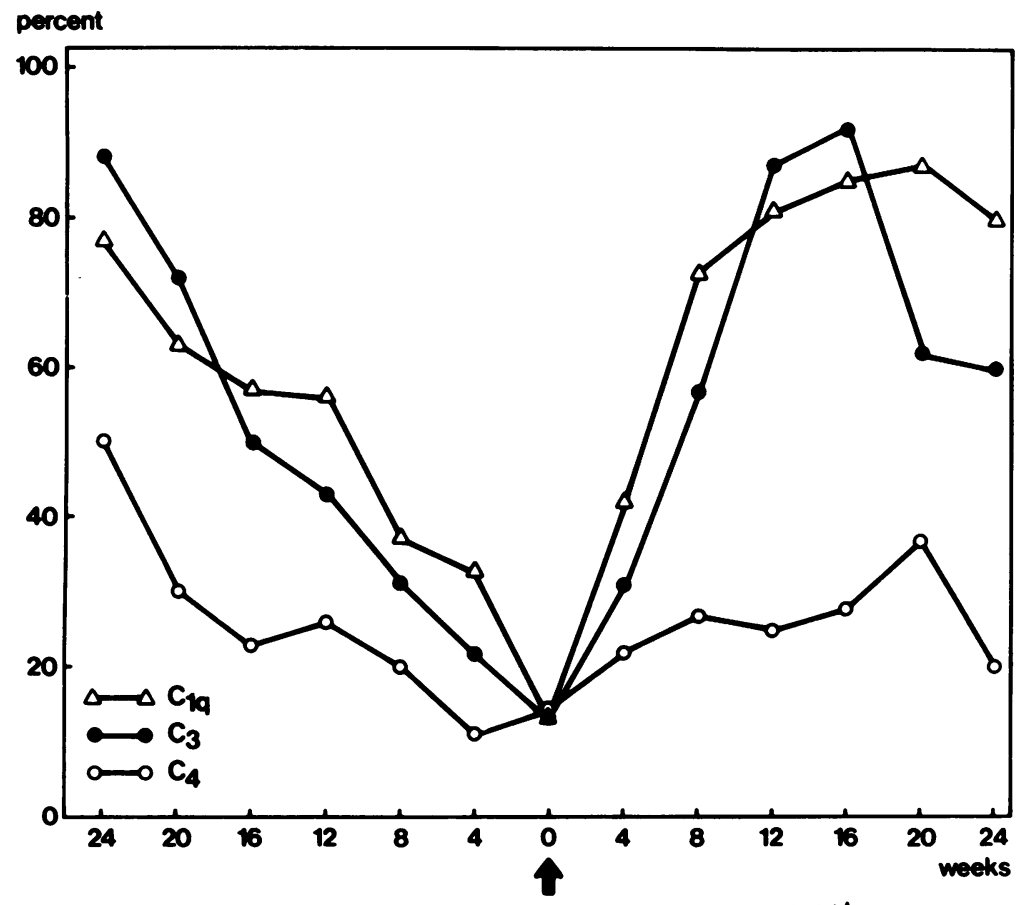

Fig. 2 The course of $\mathrm{Clq}, \mathrm{C} 3$, and $C 4$ levels in the 21 patients who developed an exacerbation of their disease with renal involvement. Each point in the figure represents the percentage of the 21 patients with levels above the 'normal' value. Note that the slope of the fall is less steep than the rise after $t=0$ (start of the exacerbation). C4 was already slightly decreased in nearly $50 \%$ of the patients 24 weeks before 'the starting point' of the exacerbation.

with decreased $\mathrm{C} 3$ and $\mathrm{C} 4$ levels, and two patients had normal $\mathrm{C} 3$ levels, with decreased $\mathrm{Clq}$ and $\mathrm{C} 4$ levels. Both Figs 1 and 2 show that in the period during and after the start of the exacerbation Clq, $\mathrm{C} 4$, and $\mathrm{C} 3$ levels tended to become normal rapidly. The increase seemed to occur faster than the decrease.

Fig. 3 shows results for $\mathrm{C} 5$ and $\mathrm{C} 9$ data; only in $40 \%$ of the patients was C 5 decreased at $t=0$. The C9 levels were slightly decreased in only one patient; in other patients all levels were normal during the follow up.

\section{COMPLEMENT PROFILES OF 12 PATIENTS}

WITHOUT RENAL INVOLVEMENT

Complement profiles of the other 12 patients who developed an exacerbation are summarised in Fig. 4 . In the period preceding the exacerbation there was a decrease in the $\mathrm{C} 4$ levels only. At time zero $60 \%$ of the patients had C4 levels lower than $37 \%$ of

Fig. 3 The course of $\mathrm{C} 5$ and $\mathrm{C} Y$ in the 21 patients who developed a deterioration of the renal function. During the whole follow up period values of $C 9$ hardly decreased. At $t=057 \%$ of the patients had normal C5 levels. C5 levels were falling at 20 weeks before the onset of the exacerbation $(t=20)$, and after $t=0$ they increased to normal.

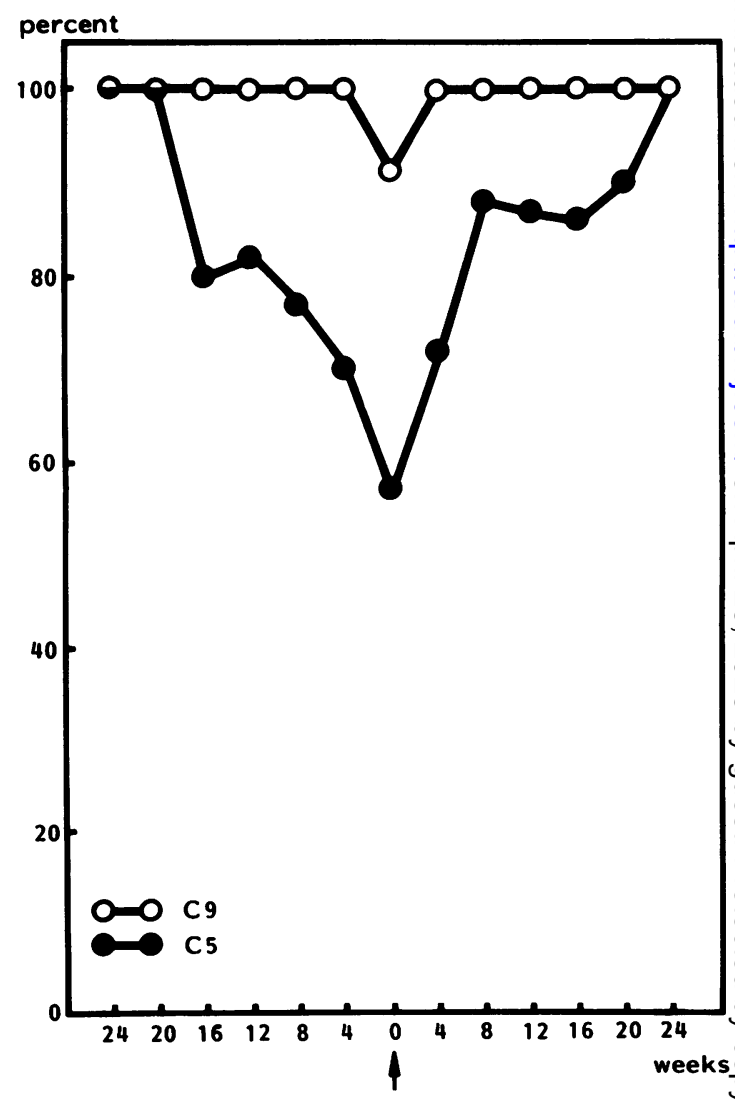




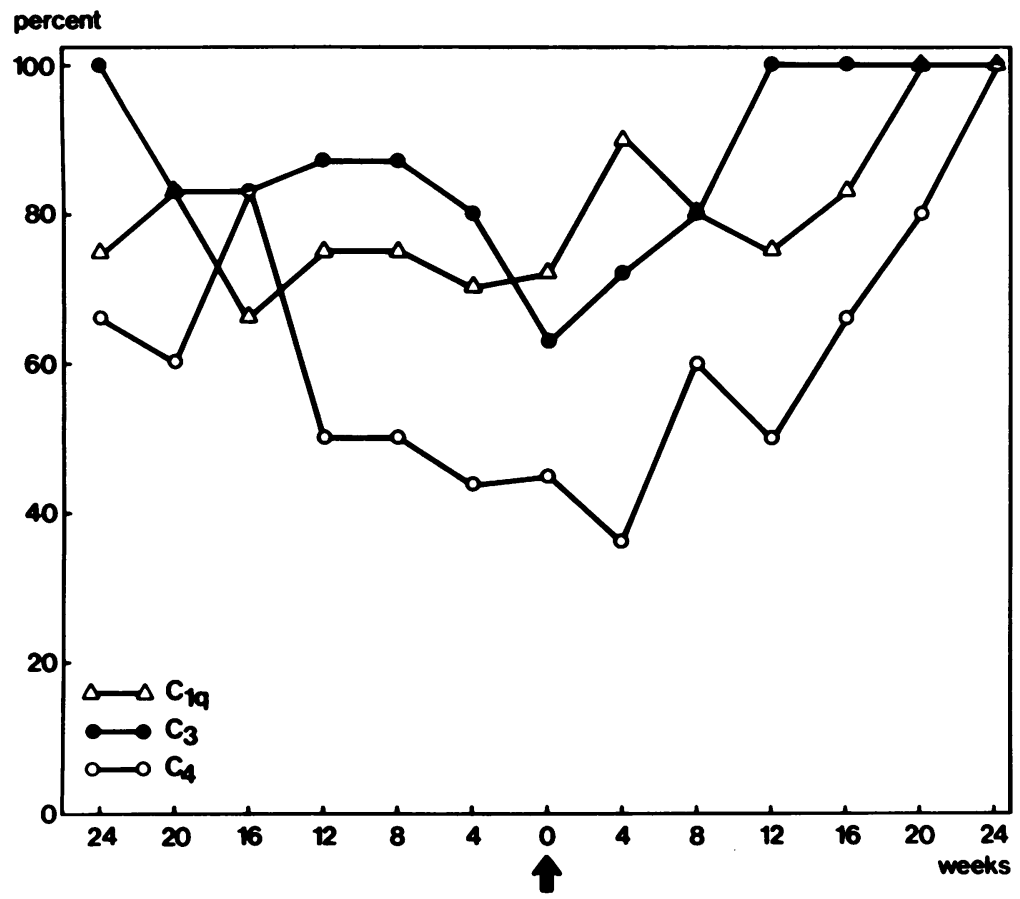

Fig. 4 The course of $C 1 q, C 3$, and $C 4$ levels in the 12 patients who developed an exacerbation of their disease but without signs of deterioration in renal function. There was a general decrease of C4. At $t=0$ nearly $60 \%$ of the patients showed decreased $C 4$ levels $(<37 \%)$. A decrease of the C4 level was already evident in $40 \%$ of the patients at 24 weeks before the onset of the exacerbation $(t=24)$. C 3 and $C l q$ levels fell in $30 \%$ of the patients.

the normal value. Of these patients, two had a decreased $\mathrm{C} 1 \mathrm{q}$ level at $\mathrm{t}=0$, with normal $\mathrm{C} 4$ and $\mathrm{C} 3$ levels, three had a decreased $\mathrm{C} 3$, with normal C1q and $\mathrm{C} 4$ levels and one had decreased $\mathrm{C} 1 \mathrm{q}$ and $\mathrm{C} 4$ levels (Fig. 5). In the patients with decreasing $\mathrm{Clq}$ levels or C3 levels, or both, no clear relation was found between the course of these levels and the developing exacerbation. During a relatively long time period preceding the exacerbation steadily decreasingly $\mathrm{C} 1 \mathrm{q}$ or $\mathrm{C} 3$ levels, or both, were found. Only the C4 levels showed the clear relation between fall and approaching exacerbation. In the $\mathrm{C} 5$ and $\mathrm{C} 9$ profiles (Fig. 6) no 'abnormalities' were detected: both complement components were always either within the normal range or increased.

\section{ANTI-dsDNA PROFILES IN THE 33 PATIENTS}

WHO DEVELOPED AN EXACERBATION

In the 24 weeks preceding exacerbations a continuous increase in the anti-dsDNA was found for all patients with a doubling time (t2) of less than 10 weeks. In 28 patients the $t 2$ was even shorter than six weeks. The actual exacerbations were characterised by rapidly decreasing levels of anti-dsDNA: 29 patients had a $t^{1 / 2}$ shorter than three weeks; the other four patients showed a $t^{1} / 2$ shorter than six weeks.
PREDICTIVE VALUE OF THE LEVELS OF COMPLEMENT COMPONENTS

Two patients in whom a deterioration of the renal function developed showed first a decrease in the $\mathrm{C} 4$ levels, followed later by falls in C1q, then $\mathrm{C} 3$ (see Fig. 1). In the non-renal patients, however, decreased complement levels were also seen. To evaluate which patients were prone to develop renal involvement at $\mathrm{t}=0$ all data of the 33 exacerbations were taken together. Firstly, the separate complement components were considered in relation to the development of renal involvement. Secondly, to increase the specificity, combinations of the complement components were examined (Table 2). For example, at $t 24$ eight out of the $33(24 \%)$ patients had a decreased C1q level. In five of these 8 patients (63\%) renal involvement developed at $\mathrm{t}=0$. At $\mathrm{t}=8$ nearly half of the 33 patients had decreased $\mathrm{C} 1 \mathrm{q}$ and/or C3 or C4. Of these patients, $75-90 \%$ developed renal involvement at $\mathrm{t}=0$. Since all patients in the period preceding the exacerbation showed increasing anti-dsDNA levels, these values meant that a patient who also developed decreasing levels of $\mathrm{Clq}$ or $\mathrm{C} 3$ and/or C4 levels lower than $40 \%$ was prone to develop renal involvement. When decreasing levels of $\mathrm{C} 1 \mathrm{q}$ and $\mathrm{C} 3$ occurred at the same time as increasing anti-dsDNA levels then a 
deterioration in the renal function could be predicted in nearly all cases. The specificity was hardly increased by addition of the $\mathrm{C} 4$ data. For the remaining 110 SLE patients, who did not have clinical signs of an exacerbation during the period of

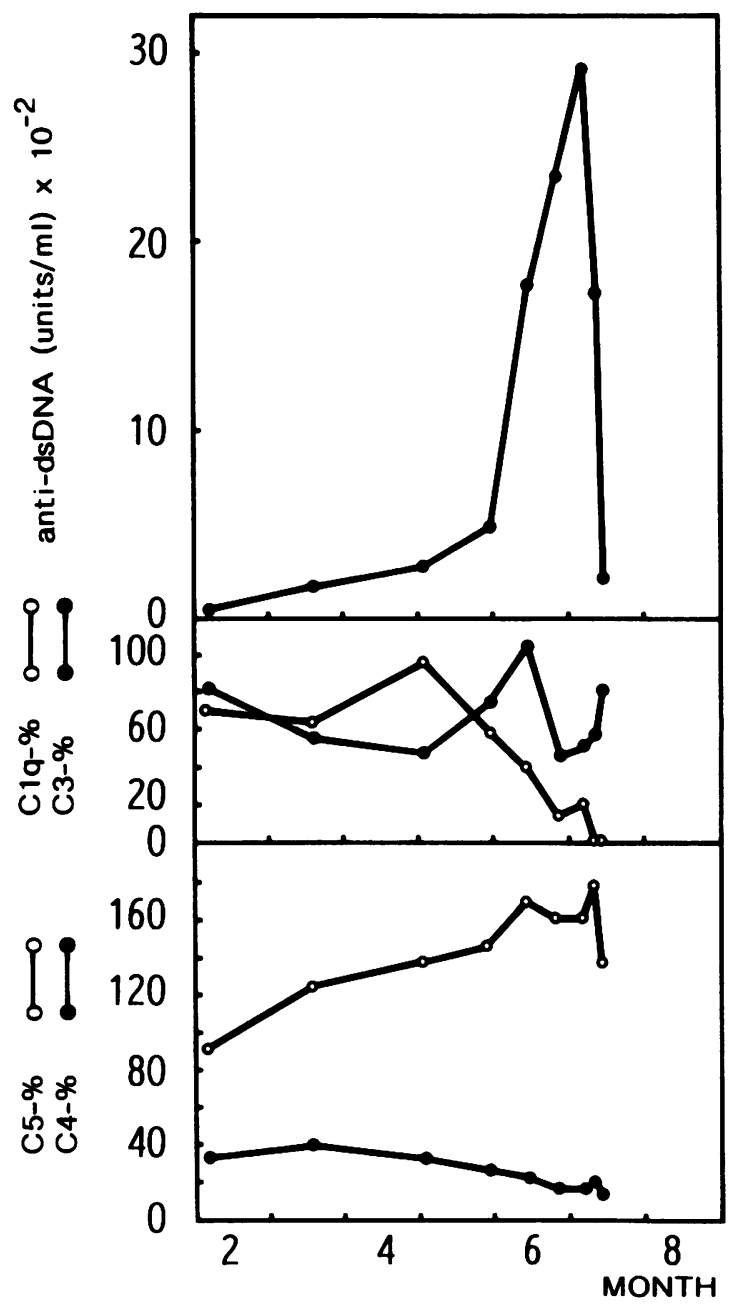

Fig. 5 Correlation between the profiles of complement components, anti-dsDNA, and course of the disease. Patient 2 was a 47 year old male, whose diagnosis of SLE was made in 1974. At that time he was admitted to hospital with pleuritic pain. Serological examination showed anaemia and leucocytopenia. Periods of polyarthritis followed. On 4 July 1982 (month 6) he entered hospital with fever $\left(40.5^{\circ} \mathrm{C}\right)$; pleuropericarditis was then diagnosed. The anti-dsDNA on $5 \mathrm{July}$ was 2960 units $/ \mathrm{ml}$, on $8 \mathrm{July} 1720$ units $/ \mathrm{ml}$, and on 11 July 216 units $/ \mathrm{ml}$. Prednisolone therapy ( $100 \mathrm{mg} /$ day) was started on 8 July. On 14 July he died due to irreversible forward cardiac failure. (Histopathological diagnosis: pericarditis, serious myocarditis.)

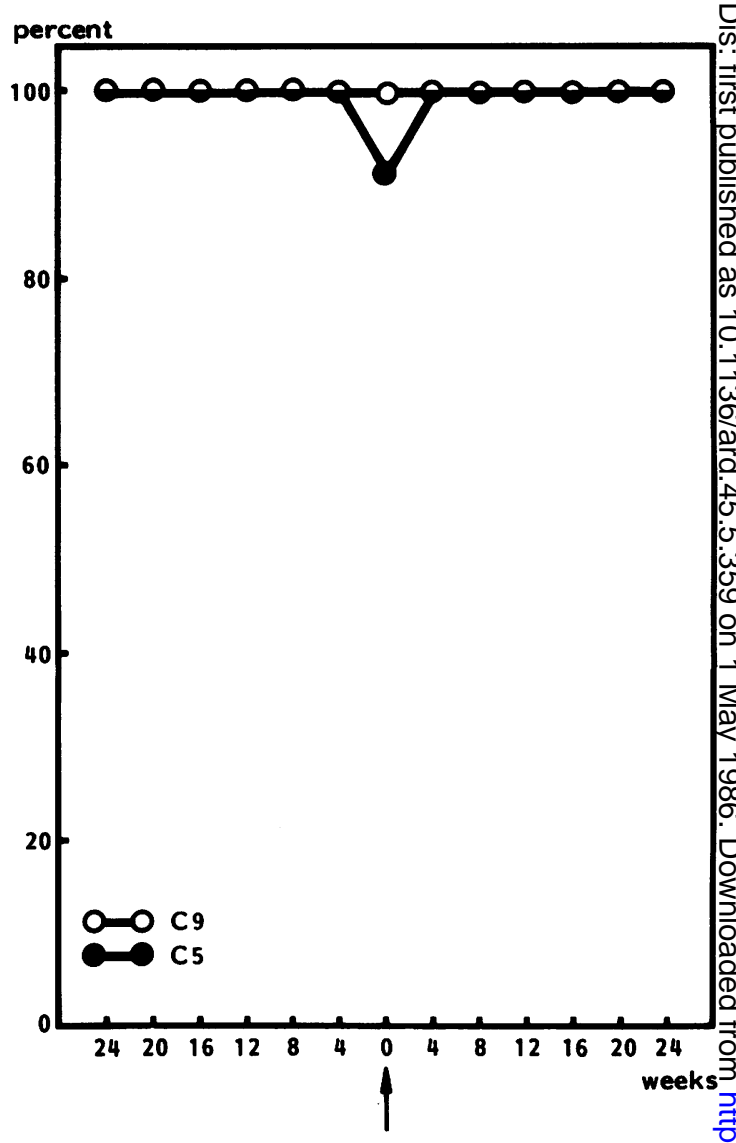

Fig. 6 Levels of C5 and C9 in 12 patients during periods of exacerbation without evidence of renal involvement.

Decreased C5 or C9 levels were detected in hardly any of these patients.

this study, increasing levels of anti-dsDNA combined with decreasing complement levels were never observed.

\section{Discussion}

The complement system is thought to be involved in the immune complex mediated lesions of SLE with deposition of complement in renal and other lesions. The level of serum complement, therefore, may represent an indicator of disease activity.

In our retrospective study ${ }^{8}$ evidence of renal ? involvement was observed when the decrease of $T$ high anti-dsDNA was accompanied by very low $\stackrel{\vec{D}}{\mathbb{D}}$ $(\leqslant 40 \%)$ serum levels of the complement factors $\cong$ $\mathrm{C} 1 \mathrm{q}$ and $\mathrm{C} 3$. In that study two out of 43 patients $\stackrel{\mathbb{2}}{2}$ were observed with low $\mathrm{C} 1 \mathrm{q}$ and normal $\mathrm{C} 3$, but neither of these two patients showed symptoms of 
Table 2 Predictive value of the levels of the complement components in the 33 SLE patients

\begin{tabular}{|c|c|c|c|c|c|c|c|c|c|c|}
\hline Time* & $C I q<40 \% \dagger$ & $R I \ddagger$ & $C 3<40 \% \dagger$ & $R I \ddagger$ & $C 4<37 \%+$ & $R I \ddagger$ & $C l q+C 3<40 \%+$ & $R I \ddagger$ & $\begin{array}{l}C l q+C 3 \leqslant 40 \% \dagger \\
+C 4 \leqslant 37 \%\end{array}$ & $R I \ddagger$ \\
\hline 24 & 24 & 63 & 7 & 100 & 50 & 83 & 0 & 0 & 0 & 0 \\
\hline 20 & 29 & 80 & 23 & 75 & 62 & 80 & 6 & 100 & 6 & 100 \\
\hline 16 & 40 & 75 & 40 & 88 & 60 & 90 & 15 & 100 & 15 & 100 \\
\hline 12 & 37 & 77 & 41 & 90 & 66 & 75 & 13 & 100 & 13 & 100 \\
\hline 8 & 50 & 83 & 50 & 90 & 70 & 75 & 29 & 100 & 29 & 100 \\
\hline 4 & 53 & 80 & 59 & 87 & 74 & 70 & 39 & 100 & 32 & 100 \\
\hline 0 & 66 & 86 & 69 & 82 & 75 & 72 & 54 & 94 & 54 & 94 \\
\hline
\end{tabular}

*Weeks preceding the onset of the exacerbation $(t=0)$.

†Te percentage of all 33 patients with decreased complement components at the defined time interval in the period preceding the exacerbation.

$\ddagger$ The percentage of the patients with decreased complement components who will develop renal involvement (RI) at time 0 .

renal impairment. Only one patient showed a deterioration in renal function with low $\mathrm{C} 1 \mathrm{q}$ and subnormal C3 (43\%) levels.

Until now the most consistent finding in patients with active SLE has been a low $\mathrm{C} 4$ level. ${ }^{15}$ Other authors regarded the presence of low levels of $\mathrm{C} 1 \mathrm{q}$ or $\mathrm{C} 4$ as special features of patients with renal involvement. ${ }^{34}$ Moreover, it was claimed that patients with renal disease tended to have lower levels of $\mathrm{C} 1 \mathrm{q}, \mathrm{C} 4$, and $\mathrm{C} 3$ than those without renal disease. ${ }^{16-19}$ Very low levels of $\mathrm{C} 1 \mathrm{q}, \mathrm{C} 3$, and $\mathrm{C} 4$ have often been reported for patients with renal disease but rarely in its absence. All the authors cited described their results from the start of the exacerbation of the disease. Ours is the first study to cover the period before the start of a flare. Only in one study on the relation between complement profiles and disease activity were results described in a prospective manner ${ }^{1}$; in that report a decrease in the $\mathrm{CH}_{50}$ titre and an increase in antinuclear antibodies were specifically noted before clinical features of exacerbations were found. Each SLE exacerbation was characterised by steadily increasing anti-dsDNA levels; overall, at the first sign of exacerbation $(t=0)$ the highest anti-dsDNA levels were reached.

The complement profiles show that if the antidsDNA increases and the various complement components $(\mathrm{C} 1 \mathrm{q}, \mathrm{C} 3$, and $\mathrm{C} 4)$ fall the patient is prone to develop an exacerbation with signs of renal involvement. Of the 33 observed exacerbations, there was only one exception to this. For a long time $\mathrm{C} 4$ levels have been considered to be the best guide for the follow up of SLE patients. One should be aware that low $\mathrm{C} 4$ levels can be observed in other diseases, for example, in viral hepatitis complicated by arthritis. ${ }^{20}$ Secondly, this study and others show that $\mathrm{C} 4$ may remain depressed over a long period of time, even in the face of an otherwise normal complement profile in the period before or after an exacerbation. ${ }^{6}$ Clear differences in C9 values in SLE patients, with or without renal involvement, have not been described. ${ }^{5}$ Moreover, in patients with, for example, membranoproliferative glomerulonephritis, normal or increased C9 levels (our findings) are found. ${ }^{21}$

Levels of $\mathrm{C} 5$ in patients with renal involvement tended to be lower than in patients without renal involvement. In this prospective study we confirmed in a larger group of patients our earlier findings of the relation between the course of the disease and the anti-dsDNA profiles. All observed periods of major flares were heralded by a period of increasing levels of anti-dsDNA. Then, once the exacerbation started, the anti-dsDNA levels decreased rapidly. Thirty three such exacerbations were observed in 143 patients. In the remaining 110 patients (none of whom developed a major exacerbation) antidsDNA levels remained constant during the time they were studied. This study was specifically focused on those patients with changing antidsDNA levels, and it became clear that changes in anti-dsDNA content associated with the three different complement components (C1q, C4, and $\mathrm{C} 3$ ) had the most prognostic significance, as follows: (a) The 21 patients who were about to develop renal involvement were characterised by an initial decrease of $\mathrm{C} 4$, followed by $\mathrm{Clq}$ and $\mathrm{C} 3$. During the phase of exacerbation $\mathrm{C} 1 \mathrm{q}$ and $\mathrm{C} 3$ increased first, followed later by $\mathrm{C} 4$ (Fig. 2). If during the follow up study of an SLE patient a continuous increase of the anti-dsDNA level (with a doubling time of four to six weeks) accompanies decreasing complement components $\mathrm{C} 1 \mathrm{q}, \mathrm{C} 3$, and $\mathrm{C} 4$, not only can an exacerbation be predicted, but also a deterioration in renal function.

(b) In nearly $10 \%$ of the SLE patients C1q or C3 were normal at the start of the renal involvement. 
These levels dropped soon after the first changes were observed.

(c) In the 12 patients who developed an exacerbation without signs of renal involvement different complement components were variably lowered. The complement component most often decreased was $\mathrm{C} 4$.

(d) C5 levels in patients with renal involvement tended to be lower than in patients without renal involvement.

(e) In both groups of patients increased levels of C9 were detected, with no clear relation with antidsDNA levels or with the course of the other complement components. Determination of C9 is thus not useful in the management of SLE.

We wish to thank Dr E Hack and Professor T E W Feltkamp for their valuable advice, Dr R J T Smeenk for reading the script critically, and Ceciel Hoeijmans, Inge Dijkstra, Pauline Roodenburg. Annette Lochtenberg, and Yvonne Kluyt for their assistance in preparing the script. This study was financially supported by the Netherlands League against Rheumatism.

\section{References}

1 Townes A S, Stewart C R, Osler A G. Immunologic studies of systemic lupus erythematosus. Johns Hopkins Med J 1962; 112: 202-18.

2 Schur P H, Sandson J. Immunological factors and clinical activity in systemic lupus erythematosus. $N$ Engl J Med 1968; 278: $533-8$.

3 Schur P H, Austen K F. Complement in the rheumatic diseases. Bull Rheum Dis 1971; 22: 666-73.

4 Lewis E J, Carpenter C B, Schur P H. Serum complement component levels in human glomerulonephritis. Ann Intern Med 1971; 75: 555-60.

5 Schur P H. Complement in lupus. Clin Rheum Dis 1975; 1: 519-43.

6 Ruddy S, Everson L K, Schur P H, Austen K F. Hemolytic assay of the ninth complement component: evaluation and depletion in rheumatic discases. Procecdings of a symposium on immune complexes and diseases. J Exp Med 1971; 134: 259-75.
7 Appel A E, Sablay L B, Golden R A, Barland P. Grayzel A T. ֻ Bank N. The effect of normalization of serum complement and anti-DNA antibody on the course of lupus nephritis. Am J Med $\vec{\equiv}$ 1978; 64: 274-83.

8 Swaak A J G. Aarden L A. Statius van Eps L W. Feltkamp? T E W. Anti-dsDNA and complement profiles as prognostic guides in systemic lupus erythematosus. Arthritis Rheum 1979: 22: 226-35.

9 Cohen A S, Reynolds W F. Franklin E G. et al. Preliminary criteria for the classification of systemic lupus erythematosus. के Bull Rheum Dis 1971: 21: 643-8.

10 Lightfoot R D, Hughes G R V. Significance of persisting. serologic abnormalities in systemic lupus erythematosus. Arthritis Rheum 1976; 5: 837-43.

11 Swaak A J G, Groenwold J, Bronsveld W. Douma J. Feltkamp T E W. Anti-dsDNA and complement profiles in systemic lupus crythematosus. Neth J Med 1981; 24: 152-6.

12 Aarden L A, Lakmaker F, de Groot E R. Immunology of DNA cr IV. Quantitative aspects of the Farr assay. J Immunol Methods or 1976; 11: 153-63.

13 Espejo R T, Canclo E S. Properties of bacteriophage $P_{2}$ : a lipid containing bacterial virus. Virology 1968: 34: 738-47. 을

14 Swaak A J G. Groenwold J. Aarden L A. Statius van Eps L w Feltkamp T E W. Prognostic value of anti-dsDNA in systemic $\vec{Z}$ lupus crythematosus. Ann Rheum Dis 1982: 41: 388-95.

15 Goldstein I N. Clinical applications of complement measurements in rhcumatic diseases. Am J Med Sci 1975; 269: 172-6. $\overrightarrow{0}$

16 Perrin L H, Lambert P H, Miescher P A. Properdin levels in $\varnothing$ systemic lupus erythematosus and membrano proliferative? glomerulonephritis. Clin Exp Immunol 1974: 16: 575-81.

17 Williams D G. Peters D K. Fallows S, et al. Studies of serum complement in the hypocomplementemic nephritides. Clin Exp Immunol 1974; 18: 391-405.

18 Gewurtz H, Pickering R J. Mergenhagen S E. Good R A. The complement profile in acute glomerulonephritis systemic lupus $\$$ erythematosus and hypocomplementemic chronic glomeruIonephritis. Int Arch Allergy 1968: 34: 566-70.

19 Kohler P F. Ten Bensel R T. Serial complement component alteration in acute glomerulonephritis and systemic lupus erythematosus. Clin Exp Immunol 1969; 4: 191-202.

20) Alper C A, Rosen F S. Studics of the in vivo behavior of human $C 3$ in normal subjects and patients. J Clin Invest 1967: 46: 2021-34.

21 Geiger H, Day N K, Good R A. The complement components $\bar{\sigma}$ $\mathrm{C} 8$ and $\mathrm{C} 9$ in sera and urines of patients with chronic 3 . proliferative glomerulonephritis. Clin Immunol Immunopathol 1973; 1: 463-71. 